\title{
Zona de Cisalhamento (Sutura) de Arroio Grande e o novo Domínio Geofísico Sudeste (Escudo Sul-Rio-Grandense): discussões baseadas em dados geofísicos e de campo
}

Rodrigo Chaves Ramos* - Programa de Pós Graduação em Geociências, Universidade Federal do Rio Grande do Sul João Angelo Toniolo - Serviço Geológico do Brasil

Luis Gustavo Rodrigues Pinto - Serviço Geológico do Brasil

Edinei Koester - Instituto de Geociências, Universidade Federal do Rio Grande do Sul

Copyright 2014, SBGf - Sociedade Brasileira de Geofísica.

Este texto foi preparado para a apresentação no VI Simpósio Brasileiro de Geofísica, Porto Alegre, 14 a 16 de outubro de 2014. Seu conteúdo foi revisado pelo Comite Técnico do VI SimBGf, mas não necessariamente representa a opinião da SBGf ou de seus associados. É proibida a reprodução total ou parcial deste material para propósitos comerciais sem prévia autorização da SBGf.

\begin{abstract}
This work presents some discussions and interpretations concerning geophysical data produced by the Escudo do Rio Grande do Sul Aerogeophysical Project (1100), conducted in 2010 by the CPRM - Geological Survey of Brazil, covering the Sul-Rio-Grandense Shield area. The magnetometry and gamma-spectrometry data, altogether with fieldwork data from recent researches in Southeastern Sul-Rio Grandense Shield (which have discovered slices of an ophiolitic complex) allowed the interpretation of a new suture in that region, the Arroio Grande Suture, and the proposal of a new geophysical domain, the Southeastern Geophysical Domain.
\end{abstract}

\section{Introdução}

$\mathrm{Na}$ década de 1990, estudos geofísicos foram de fundamental importância para embasar algumas hipóteses a respeito das divisões tectônicas do Escudo Sul-Rio-Grandense. A partir de técnicas gravimétricas e aeromagnetométricas, Fernandes et al. (1995) e Costa (1997) dividiram o Escudo em três domínios geofísicos principais (Oeste, Central e Leste), separados por descontinuidades gravimétricas e aeromagnetométricas denominadas de Sutura de Porto Alegre (que separa os domínios Leste e Central), Sutura de Caçapava (que separa os domínios Central-Leste e Oeste) e Sutura de São Gabriel (que separa o domínio Central-Oeste do Oeste). Essas divisões auxiliaram na definição mais precisa dos limites das associações petrotectônicas reconhecidas no Escudo até aquele momento. Esses autores ressaltaram ainda que a região sul do Domínio Geofísico Leste apresentava importantes anomalias geofísicas que deveriam ser investigadas com mais atenção, numa região que coincidentemente carecia na época de informações geológicas detalhadas.

Em 2010 o Projeto Aerogeofísico Escudo do Rio Grande do Sul (Projeto 1100) atualizou as informações geofísicas do Escudo. Essas informações, aliadas às recentes descobertas de Ramos e Koester (2014 a, b), que reconheceram na região sudeste do Escudo fragmentos ofiolíticos encaixados em uma zona de cisalhamento de escala regional, levantaram a discussão de que essa região possa corresponder a um domínio geofísico distinto do Domínio Geofísico Leste, separados por uma possível sutura representada pela referida zona de cisalhamento. O presente trabalho apresenta dados referentes ao Projeto 1100 e discussões sobre uma possível nova compartimentação geofísica do Escudo, baseada nos dados geofísicos e geológicos aqui apresentados.

\section{Interpretação aerogeofísica qualitativa}

No Projeto 1100, desenvolvido na área apresentada na Figura $1 \mathrm{~A}$, as linhas de voo (LV) apresentaram direção N-S com espaçamento de $500 \mathrm{~m}$ entre as mesmas e linhas de controle (LC) espaçadas de $5 \mathrm{~km}$ com direção E-W. A frequência de leitura dos dados foi de aproximadamente uma leitura a cada segundo para os dados gamaespectométricos (equivalente a $70 \mathrm{~m}$ ao longo da LV) e de dez leituras por segundo para os dados magnetométricos (equivalente a $7 \mathrm{~m}$ ao longo da LV), sendo a altura de voo de $100 \mathrm{~m}$ com relação ao solo.

O processamento de dados teve por objetivo a geração de diferentes temas sob a forma de grids. Nesse processamento adotou-se como espaçamento na interpolação dos dados 0 valor de $1 / 4$ do espaçamento das LV de $125 \mathrm{~m}$.

$\mathrm{Na}$ geração dos grids utilizou-se o software Oasis Montaj (Versão 8.1) da Geosoft. Os mapas gerados foram os magnetométricos: Campo Magnético Residual (nT - nanoTesla), Primeira Derivada Vertical $\left(n T /{ }^{\circ}\right)$ e Sinal Analítico do Campo Magnético Residual (nT/o); e os Gamaespectrométricos: Contagem Total ( $\mu \mathrm{R} / \mathrm{h})-$ microRoentgen/h), Tório (ppm), Urânio (ppm), Potássio (\%) e de Composição Ternária dos três elementos (U, Th, K). Estes mapas foram utilizados nas interpretações aqui realizadas.

De modo geral, o estudo restringiu-se à análise de feições geofísicas circunscritas, a partir dos contrastes laterais de propriedades físicas de minerais (susceptibilidade magnética e emissão de radiação gama - elementos Th, U e K) que compõem as litologias do terreno sobrevoado recoberto pelo levantamento. Os sinais físicos foram emitidos pelo terreno e registrados por sensores posicionados diretamente abaixo da linha do levantamento aerogeofísico. A partir de tabelas de propriedades físicas das rochas, juntamente com as intensidades e as formas das feições geofísicas obtidas no processamento dos dados aéreos (imagens dos grids), pode-se sugerir a existência de determinados tipos litológicos e/ou estruturas geológicas nos terrenos.

\subsection{Magnetometria}

Os mapas magnetométricos contribuíram com informações relacionadas à geologia estrutural da área, e se mostraram úteis para a definição do arcabouço tectonoestrutural da região. 


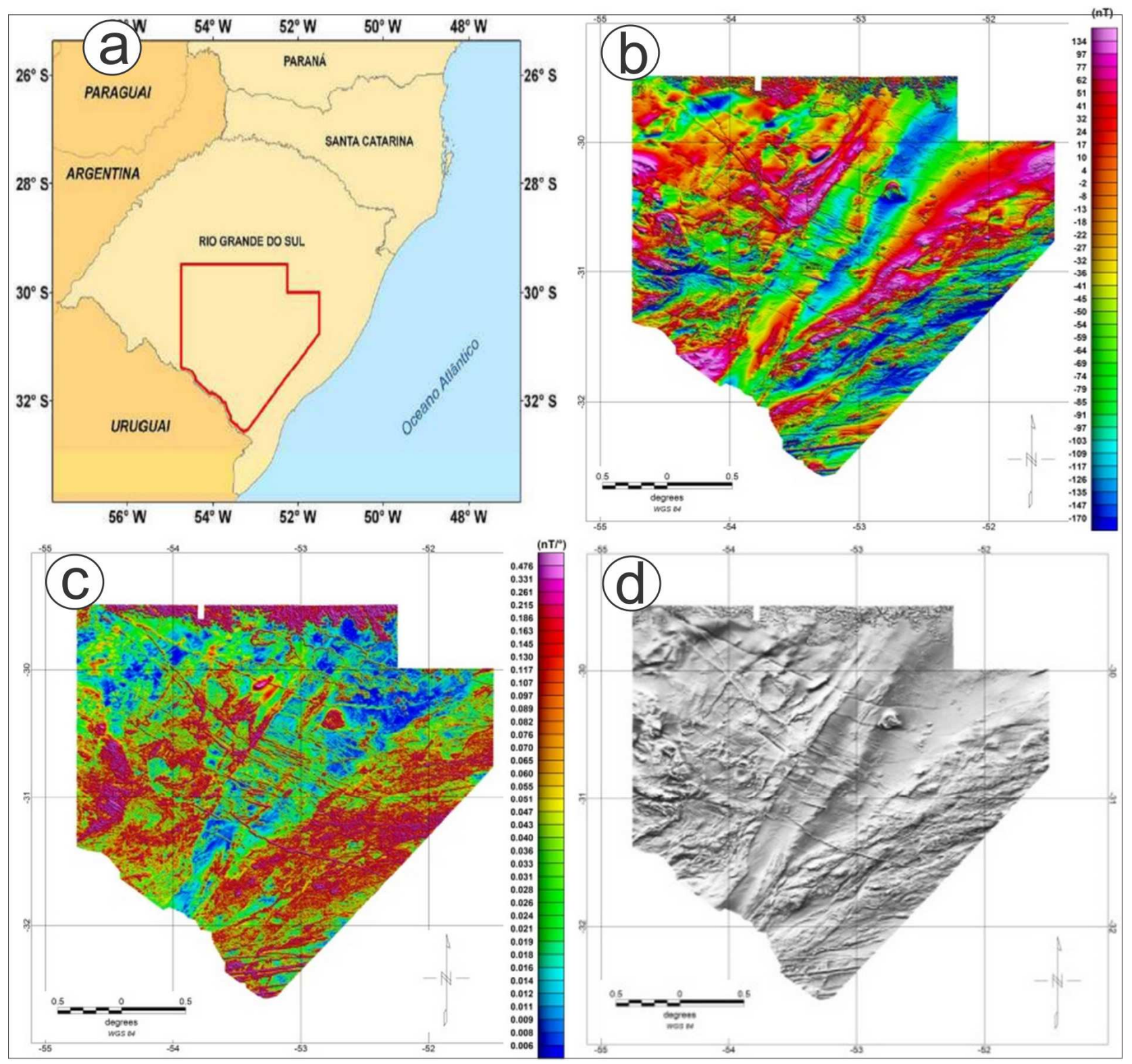

Figura 1 - (A) Área do levantamento geofísico (polígono vermelho) do Projeto 1100; (B) Mapa magnetométrico do campo total reduzido do IGRF; (C) Mapa do sinal analítico do campo magnético total. Anomalias em magenta/vermelho representam rochas com alta magnetização e, em azul, rochas com pouca ou ausentes de magnetização; (D) Mapa da primeira derivada vertical do campo magnético total.

\subsubsection{Campo magnético total}

A Figura 1B mostra o mapa de campo magnético total reduzido do International Geomagnetic Reference Field (IGRF). Nota-se uma característica comum a esse tipo de mapa, que é a bipolaridade. Esta reflete a existência de valores positivos (em magenta/vermelho) associados a valores negativos (em azul) representando um único corpo magnético.

\subsubsection{Sinal analítico}

A realização do sinal analítico em um mapa magnetométrico do campo total reduzido do IGRF é um artifício matemático utilizado para que as anomalias magnéticas, que inicialmente possuem um caráter bipolar, passem a ser monopolar (Figura 1C). Outra utilidade deste método é que a amplitude do sinal fica posicionada imediatamente acima dos limites das estruturas/corpos, facilitando assim a identificação e o posicionamento dos corpos magnéticos ou nãomagnéticos.

\subsubsection{Primeira derivada}

A aplicação da primeira derivada vertical do campo magnético total reduzido do IGRF caracteriza-se por realçar as estruturas magnéticas (falhas/fraturas e diques magnéticos). Na Figura 1D nota-se que, na área, a predominância de alinhamentos magnéticos associados a falhas/fraturas e diques magnéticos dá-se na direção SW-NE. 


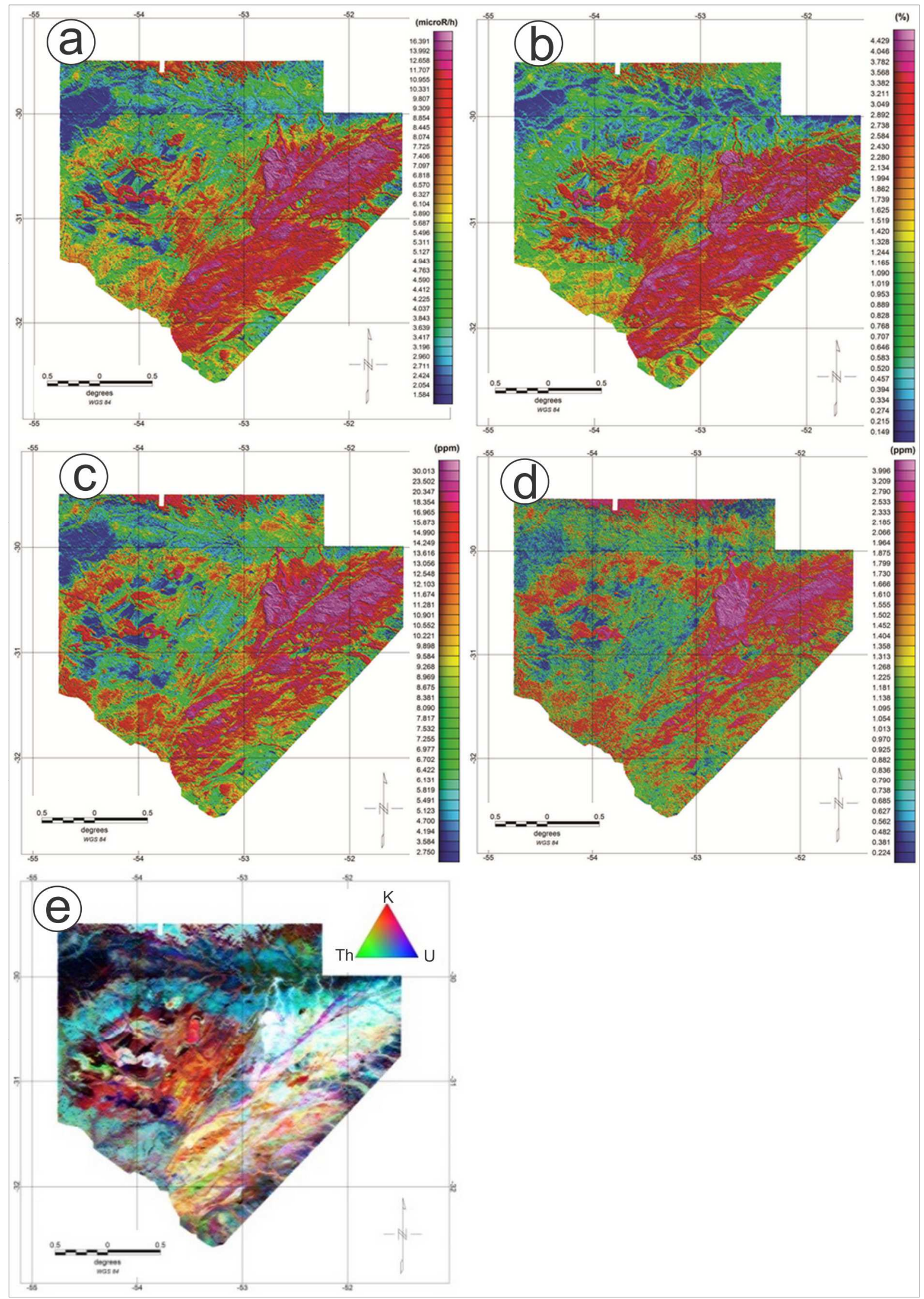

Figura 2 - Mapas gamaespectrométricos de (A) Contagem Total, (B) Potássio, (C) Tório, e (D) Urânio; (E) Mapa de composição ternária dos respectivos elementos. 
Existem, porém, outros alinhamentos magnéticos perpendiculares, cortando 0 trend principal dos alinhamentos predominantes. Destaca-se ainda no extremo sul do levantamento aerogeofísico o domínio de alinhamentos $\mathrm{N} 80^{\circ} \mathrm{W}$ a E-W.

\subsection{Gamaespectrometria}

Os mapas dos radioelementos Th, $\mathrm{U}$ e $\mathrm{K}$ correspondem à geologia de superfície e representam a distribuição das diferentes rochas e solos aflorantes. Os níveis radiométricos inicialmente medidos em choques por segundo (cps) estão convertidos para concentrações de $U$ e Th (em ppm) e K (em \%), através do método backcalibration. A Contagem Total é expressa como taxa de exposição, em $\mu \mathrm{R} / \mathrm{h}$ (micro Röengten por hora) observado na Figura 2A, B, C e D. A composição ternária $R G B$ dos canais $K$, Th e $U$, respectivamente, são observadas na Figura $2 \mathrm{E}$.

\section{Geologia}

A interpretação geológica dos mapas geofísicos mostrados nas figuras anteriores, e em especial o mapa da primeira derivada vertical do campo magnético total permitiu reacender discussões prévias (Fernandes et al., 1995; Costa, 1997) acerca da possível existência de um domínio geofísico distinto no sudeste do Escudo Sul-Rio-Grandense, à luz de novas e recentes informações geológicas da região (e.g. Ramos e Koester, 2014 a, b). Sobre o referido mapa (Figura 3), foram traçados os principais lineamentos geológicos e geofísicos que são reconhecidos como limites de domínios geofísicos já definidos pelos supramencionados autores. Na figura foi acrescentada a Zona de Cisalhamento Arroio Grande, que juntamente com as zonas de cisalhamento de Herval e Ayrosa Galvão (Philipp, 1998) (ver Figura 5), formam a aqui denominada Sutura de Arroio Grande, que delimitaria um novo domínio geofísico no sudeste do Escudo Sul-Rio-Grandense.

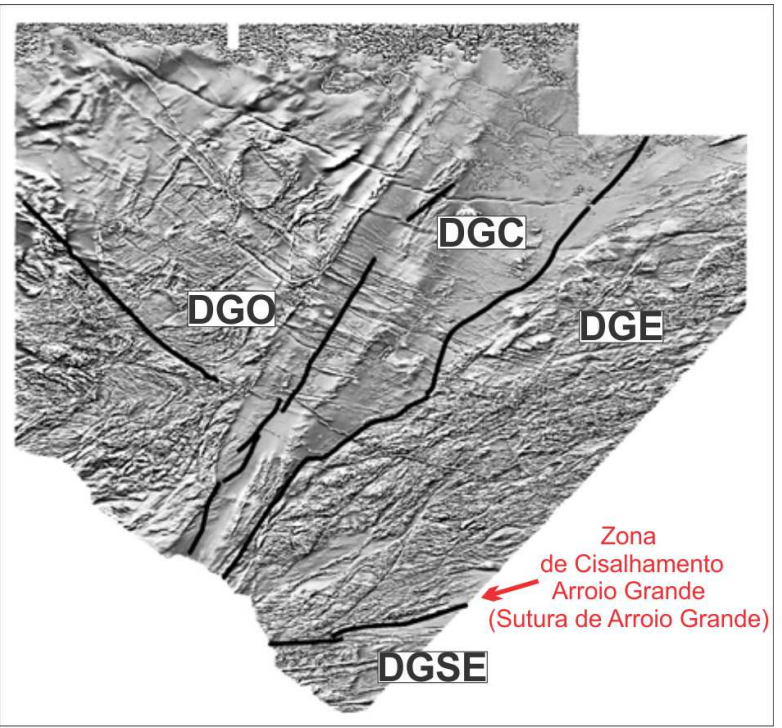

Figura 3 - Mapa da Primeira Derivada Vertical, com destaque para as principais descontinuidades geofísicas na porção sudeste do Escudo Sul-RioGrandense (conforme Fernandes et al. 1995, e Costa, 1997) e os aqui propostos Sutura de Arroio Grande e
Domínio Geofísico Sudeste. Legendas: DGO= Domínio Geofísico Oeste; DGC = Domínio Geofísico Central; $D G E$ = Domínio Geofísico Leste; DGSE = Domínio Geofísico Sudeste.

O novo domínio geofísico proposto apresenta as seguintes características geofísicas: (i) lineamentos de direção $\mathrm{N} 80^{\circ} \mathrm{W}$ a $\mathrm{E}-\mathrm{W}$, que são singulares e distintos dos principais lineamentos de outros terrenos mais ao Norte; (ii) rochas empobrecidas em potássio - padrão de cores azul-esverdeado (ver mapa ternário da Figura 4) - em contraste ao restante do domínio ao Norte/Nordeste, que apresenta padrões em tons de amarelo e vermelho devido à presença de rochas mais ricas em potássio.

Os alinhamentos desse domínio, quando lançados sobre o mapa geológico do Rio Grande do Sul de Wildner et al. (2008) e Ramos e Koester (2014b), têm como correspondente litológico o Granito Arroio Grande (Figura 5), classificado como leucogranito a duas micas, de granulação grossa, com foliação milonítica e encraves gnáissicos. Também sobrepõem afloramentos de uma associação meta-ultramáficamáfica-sedimentar recentemente interpretada por Ramos e Koester (2014a, b) como fragmentos metamorfizados de um complexo ofiolítico, denominado de Complexo Ofiolítico Arroio Grande. Essa interpretação foi formulada a partir de relações de campo e associação litológica (Figura 5) e reforçada por evidências petrográficas e principalmente litogeoquímicas, que apontam uma origem mantélica e crustal oceânica para as unidades metaígneas (Ramos e Koester, 2014a, b).

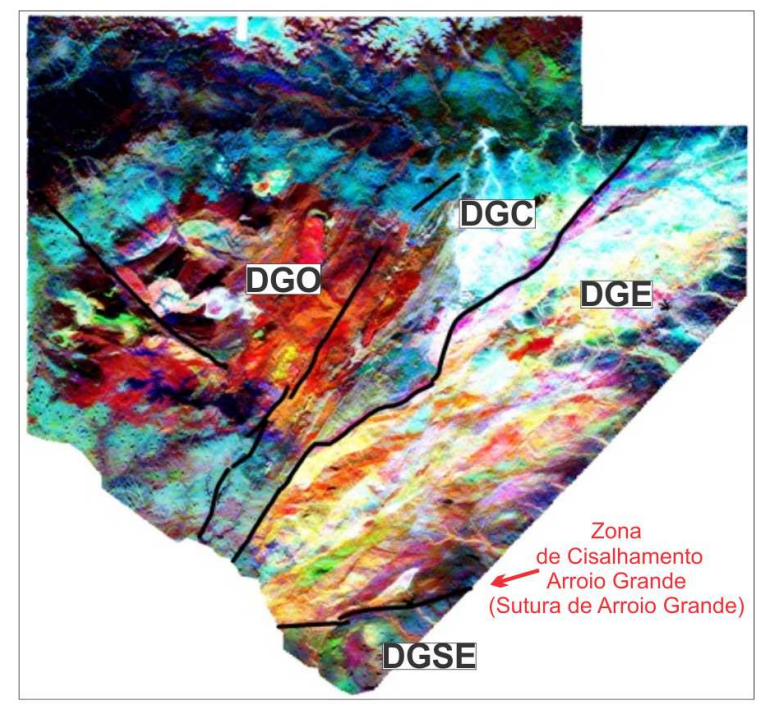

Figura 4 - Mapa dos elementos $K$, Th e $U$ do Projeto 1100.

O Complexo Ofiolítico Arroio Grande é limitado a N e W pelo Granito Arroio Grande e a S e E por outros granitoides. Suas litologias são afetadas por zonas de cisalhamentos dúcteis subverticais de direção preferencial $\mathrm{N} 50-80^{\circ} \mathrm{E}$ e, secundariamente, E-W (Figura 5). Tais zonas de cisalhamento são responsáveis pela deformação e milonitização encontradas na maioria das rochas pertencentes às unidades formadoras do Complexo: unidade 
metaultramáfica, unidade metamáfica e unidade metassedimentar.

A unidade metaultramáfica é representada por talco xistos (constituídos por agregados de talco e serpentina, ambos $\approx 50-70 \%$, além de tremolita, clorita e cromita) (Figura $6 \mathrm{~A}$ ), tremolititos $(\approx 90 \%$ de tremolita, e clorita, talco e cromita subordinados) e clorititos (95 $\%$ Cr-clorita e subordinadamente serpentina, tremolita e ilmenita) (Figura 6B), que constituem corpos métricos a decamétricos, descontínuos e alongados na direção NE-SW que são frequentemente encontrados em um mesmo afloramento em contato gradacional. Essas litologias apresentam granulação fina a média, xistosidade milimétrica subvertical, lineações de estiramento sub-horizontais, frequente presença de dobras e, localmente, clivagens de crenulação.

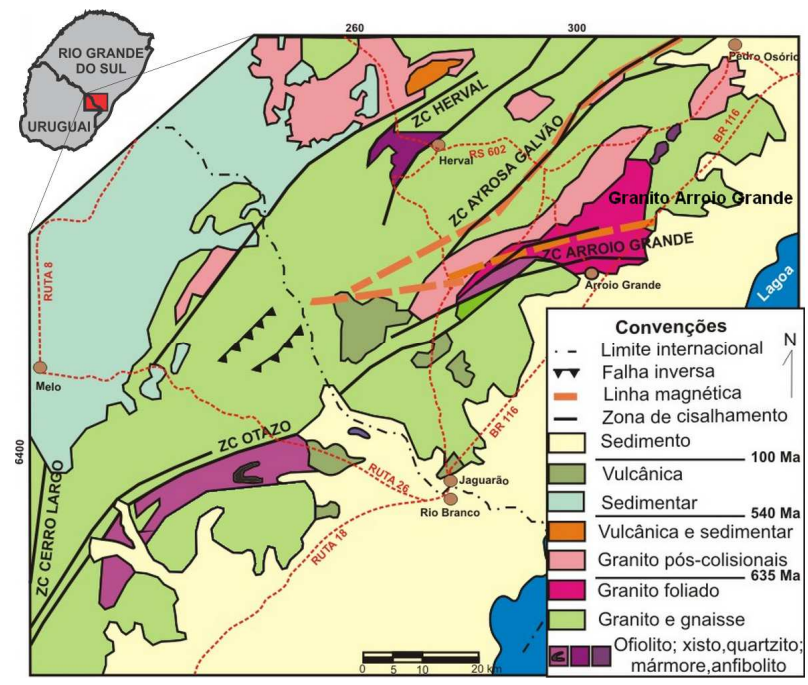

Figura 5 - Mapa geológico do extremo sul do Escudo Sul-Rio-Grandense e porção nordeste do Escudo Uruguaio (modificado de Ramos e Koester, 2014b).

A unidade metamáfica é representada por anfibolitos $(\approx 30-55 \%$ hornblenda, $\approx 20-40 \%$ plagioclásio, $\approx 5-20 \%$ epidoto e $\approx 5-10 \%$ quartzo, além de biotita e clorita) (Figura $6 \mathrm{C}$ ), e metagabros $(\approx$ $40-50 \%$ hornblenda, $\approx 30 \%$ augita, $\approx 30 \%$ plagioclásio, $\approx 5-10 \%$ quartzo, além de clorita, biotita e pirita) (Figura 6D). Os anfibolitos formam corpos descontínuos, métricos a decamétricos, alongados na direção NE-SW. Apresentam granulação fina e bandamento milimétrico, irregular e descontínuo, marcado por quartzo e plagioclásio. Os metagrabos têm granulação média a grossa e são encontrados como xenólitos centimétricos a métricos nos granitoides da região (Granito Arroio Grande e outros granitoides).

A unidade metassedimentar é constituída por micaxistos (granulação fina, $\approx 40 \%$ quartzo, $\approx 25-30 \%$ muscovita, $\approx 15 \%$ biotita e $\approx 15 \%$ plagioclásio) (Figura $6 \mathrm{E}$ ), metagrauvacas (granulação muito fina a fina, composição quartzo-feldspática com $\approx 50 \%$ de pseudomatriz argilosa) (Figura 6F), granada-biotita xistos (granulação fina, $\approx 40 \%$ biotita, $\approx 30 \%$ quartzo, $\approx 15 \%$ feldspato alcalino, $\approx 10 \%$ granada e opacos) (Figura 6G), e mármores (granulação fina a média, $\approx$ $70 \%$ calcita, $\approx 15 \%$ diopsídio além de $\approx 5-10 \%$ titanita e opacos) (Figura $6 \mathrm{H}$ ). Os micaxistos formam corpos métricos a quilométricos, associados a lentes centimétricas a métricas de quartzitos, e também tectonicamente intercalados com granitoides, rochas metaultramáficas/metamáficas, metagrauvacas e granada-biotita xistos. Os mármores formam lentes quilométricas com intercalações centimétricas a métricas de rochas calcissilicáticas e anfibolíticas, encaixadas em granitoides. As metagrauvacas formam corpos métricos a decamétricos, geralmente em contato com injeções leucograníticas centimétricas a métricas dobradas.

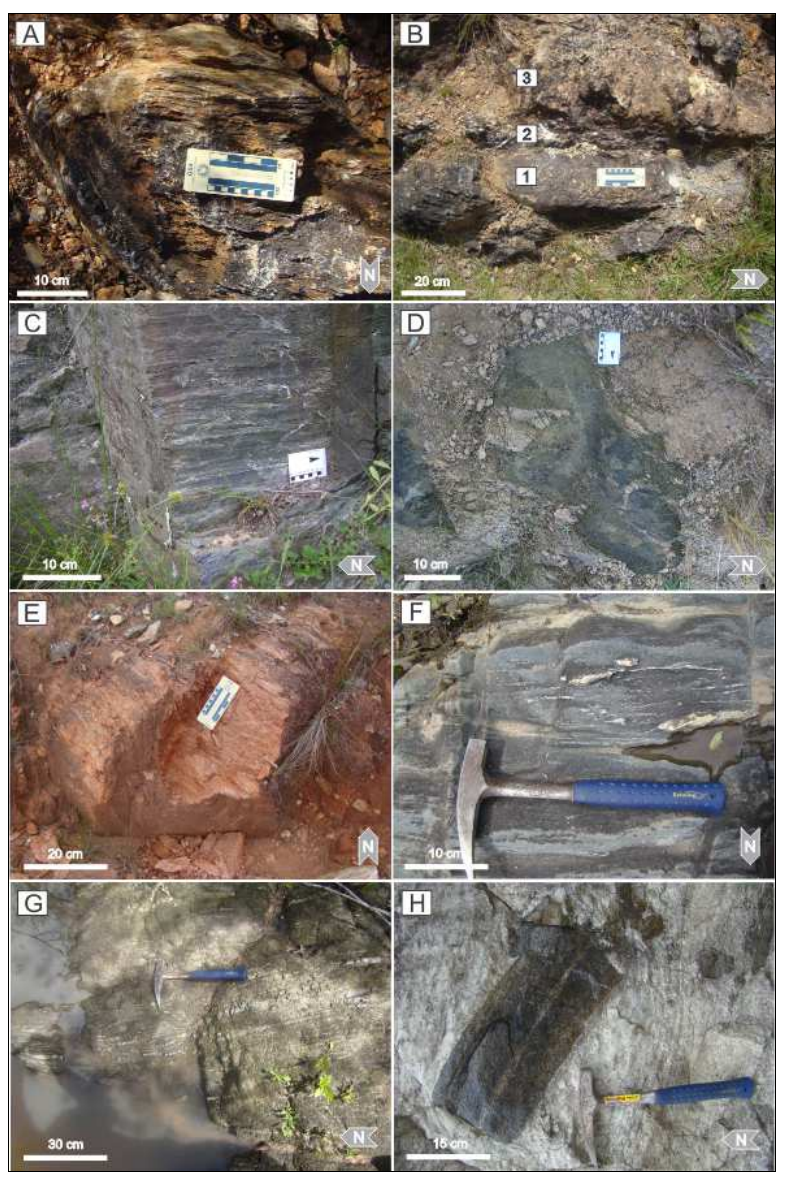

Figura 6 -Afloramentos: (A) lente de tremolita-talcoserpentina xisto dobrado; (B) camadas de talco xisto (1), cloritito (2) e tremolitito (3) em contato; (C) epidoto anfibolito; (D) xenólitos de metagabro no Granito Arroio Grande; $(E)$ micaxisto; $(F)$ metagrauvaca; $(G)$ granadabiotita xisto; $(H)$ mármore e fragmento de anfibolito (porção escura).

\section{Discussões e Conclusões}

Os dados geofísicos de aerogamaespectrometria e aeromagnetometria do Projeto 1100 demonstraram a existência de uma importante descontinuidade geofísica na região sudeste do Escudo Sul-RioGrandense. Em conjunto com os dados de levantamentos geológicos que apontam a existência de fragmentos ofiolíticos - as únicas ocorrências de rochas ultramáficas e mármores encontradas até 0 momento em toda a porção leste do Escudo, o que ressalta a exoticidade litológica dessa área - nessa região, sugere-se aqui um novo domínio geofísico, o Domínio Geofísico Sudeste. 
Este novo domínio seria limitado do Domínio Geofísico Leste pela Zona de Cisalhamento de Arroio Grande. Essa zona de cisalhamento contém encaixadas as rochas do complexo ofiolítico e coincide com a área onde os padrões geofísicos do Domínio Geofísico Leste mudam de direção preferencial. Por esses motivos, a referida zona de cisalhamento foi aqui tratada como uma sutura.

Com isto, fica evidenciada a importância do aporte e integração de dados geofísicos do Projeto 1100, que aliados a informações básicas de campo, contribuem para as discussões e modelamentos geotectônicos do paleocontinente Gondwana Ocidental na região sul do Brasil.

\section{Agradecimentos}

Ao CNPq (proc. PQ 305853/2010-4) e FAPERGS (proc. PqG 10/1509-0).

\section{Referências}

Costa, A.F.U., 1997. Teste e modelagem geofísica da estruturaçao das associações litotectônicas précambrianas no escudo sul-rio-grandense. Tese (Doutorado em Geociencias) - Instituto de Geociências, Universidade Federal do Rio Grande do Sul. Porto Alegre, v.1, $180 \mathrm{f}$.

CPRM - Serviço Geológico do Brasil, 2010. Projeto Aerogeofísico Escudo do Rio Grande do Sul: relatório final do levantamento e processamento dos dados magnetométricos e gamaespectométricos. Rio de Janeiro: Lasa Prospecções, 2010. 27 v. Programa Geologia do Brasil - PGB.

Fernandes, L.A.D., Menegat, R., Costa, A.F.U., Koester, E., Porcher, C.C., Tommasi, A., Kraemer, G., Ramgrab, G.R., Camozzato, E., 1995. Evolução tectônica do Cinturão Dom Feliciano no Escudo Sulriograndense: Parte II - Uma contribuição a partir das assinaturas geofísicas. Revista Brasileira de Geociências, 25(4) : 375-384.

Kearey, P., Brooks, M., Hill, I., 2009. Geofísica de Exploração. Oficina de Textos, São Paulo, 438 p.

Philipp, R.P., 1998. A evolução geológica e tectônica do Batólito Pelotas no Rio Grande do Sul. Tese (Doutorado em Geociências) - Instituto de Geociências, Universidade de São Paulo. São Paulo, 255 f.

Ramos, R.C. \& Koester, E., 2014a. Geologia da associação metamáfica-ultramáfica da região de Arroio Grande, sudeste do Escudo Sul-Rio-Grandense. Pesquisas em Geociências, 41(1) : 25-38.

Ramos, R.C. \& Koester, E., 2014b. Lithogeochemistry of the meta-igneous units from Arroio Grande Ophiolitic Complex, southernmost Brazil. Brazilian Journal of Geology, submetido.

Robinson, E.S., \& Çoruh, C., 1988. Basic Exploration geophysics. John Wiley \& Sons, Canadá, 562 p.
Wildner, W., Ramgrab, G.E., Lopes, R.C., Iglesias, C.M.F., 2007. Geologia e Recursos Minerais do Estado do Rio Grande do Sul. Escala 1:750.000. CPRM Serviço Geológico do Brasil, Programa Geologia do Brasil, Mapas geológicos Estaduais. Porto Alegre, 1 DVD. 